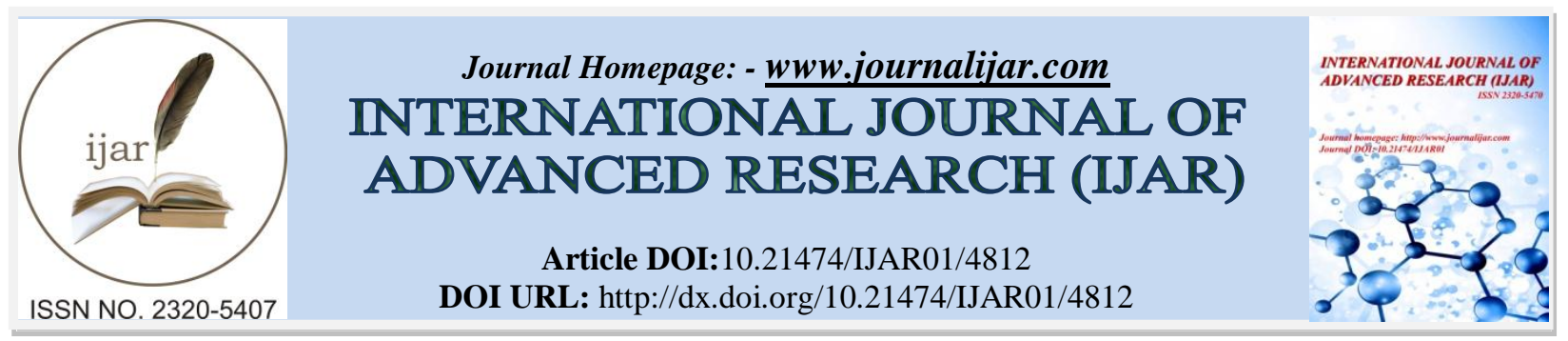

RESEARCH ARTICLE

\title{
EFFECT OF COBALT FERRITE ON ELECTRICAL AND MAGNETIC PROPERTIES OF BISMUTH FERRITE.
}

${ }^{*}$ H. Hemanta, H. Basantakumar Sharma.

Department of Physics, Manipur University, Canchipur-795003, India.

\section{Manuscript Info}

Manuscript History

Received: 11 May 2017

Final Accepted: 13 June 2017

Published: July 2017

Key words:-

multiferroic, nanocomposite, dielectric, magnetic property.

\section{Abstract}

The ferromagnetic material of bismuth ferrite and cobalt ferrite are synthesized by using the sol gel auto-combustion method. The different composites of bismuth and cobalt ferrite are prepared (1-x) $\mathrm{BiFeO}_{3}-\mathrm{xCoFe}_{2} \mathrm{O}_{4} \quad(\mathrm{x}=0.0,0.2,0.5,0.8,1)$. The samples are characterized by X-ray diffraction (XRD), scanning electron microscopy (SEM) and impedance spectroscopy. XRD pattern of bismuth ferrite and cobalt ferrite shows the rhombohedral and cubic spinel structure respectively. All the samples showed dispersion relation with frequency. The pure BFO sample shows the weak ferromagnetic properties with coercivity $H_{c}=209.510 e$ and magnetization of $\mathrm{M}_{\mathrm{s}}=4.723 \mathrm{emu} / \mathrm{g}$ at room temperature. All the samples show the ferromagnetic nature and there is increase in both saturation magnetization and remanence magnetization with decrease in bismuth ferrite contents in the composite samples. However there is variation in coercivity and is found to be maximum for the composite sample with $\mathrm{x}=0.8$. The current - voltage $(\mathrm{I}-\mathrm{V})$ characteristic of $\mathrm{BFO}$ sample shows the non-ohmic nature while cobalt ferrite shows ohmic nature.

Copy Right, IJAR, 2017,. All rights reserved.

\section{Introduction:-}

The multiferroic materials combining both ferroelectric and ferromagnetic phase have attracted extensive interest in the field of solid state physics and various technological fields. The magnetoelectric (ME) coupling property of the materials enable electrical polarization by magnetic field and conversely, magnetization by varying electric field [13]. Bismuth ferrite (BFO) is a well known single phase multiferroic material having distorted perovskite structure with anti-ferromagnetic Neel temperature $\left(\mathrm{T}_{\mathrm{N}} \sim 370^{\circ} \mathrm{C}\right)$ and ferroelectric Curie temperature $\left(\mathrm{T}_{\mathrm{C}} \sim 850^{\circ} \mathrm{C}\right)[4]$. Bismuth ferrite and bismuth ferrite based multi-ferroic materials are widely used in ceramics and thin films forms [5-9]. The ferroelectric property of BFO is very excellent but it has weak ferromagnetic property. Many researchers tried to enhance the magnetization and $\mathrm{ME}$ effect in the highly constrained epitaxial thin films and chemically substituted films and ceramics. But it is still in vain. This leads to the weak ME effect for these materials. So for the real application these weak ME materials cannot be applicable.

\section{Experiment:-}

The bismuth ferrite and cobalt ferrite are synthesized by using the sol gel auto-combustion technique separately. In this method equal amount of ethylene glycol and 2-mthoxy ethanol are mixed and stir for about 30 minutes. Then, acetic acid is added drop wise till the $\mathrm{pH}$ value of the solution is adjusted to 1 . The mixture is stirred uniformly for 
30 minutes and is used as a standard solution. Stoichiometric amount of analytical grade bismuth nitrate pentahydrate $\left[\mathrm{Bi}\left(\mathrm{NO}_{3}\right)_{3} .5 \mathrm{H}_{2} \mathrm{O}\right]$ is added and stir for 30 minutes and then stoichiometric amount of ferric nitrate nonahydrate $\left[\mathrm{Fe}\left(\mathrm{NO}_{3}\right)_{3} .9 \mathrm{H}_{2} \mathrm{O}\right]$ is also added. The solution is heated with continuous stirring at a temperature of $70^{\circ} \mathrm{C}$ for about 3 hours. Then temperature is raised and yellow precipitate is formed. The precipitate so formed is found to be hygroscopic and so it is heated at high temperature to vaporize all the water content of the samples. After some time the powder in the bottom of beaker starts burning and becomes black with evolution of white colored gases.

The powder is annealed at $500^{\circ} \mathrm{C}$ for obtaining crystalline powder followed by leaching with dilute nitric acid to remove the parasitic phases.

The cobalt ferrite powder is prepared by sol gel auto-combustion method by using the analytical grade of cobalt nitrate hexahydrate $\left[\mathrm{Co}\left(\mathrm{NO}_{3}\right)_{3} \cdot 6 \mathrm{H}_{2} \mathrm{O}\right]$, ferric nitrate nonahydrate $\left[\mathrm{Fe}\left(\mathrm{NO}_{3}\right)_{3} \cdot 9 \mathrm{H}_{2} \mathrm{O}\right]$ and citric acid $\left[\mathrm{C}_{6} \mathrm{H}_{8} \mathrm{O}_{7}\right] . \mathrm{Citric}$ acid is used as a fuel. Stoichiometric amount of the metal nitrates are dissolved in de-ionized water by stirring on a hot plate at $100^{\circ} \mathrm{C}$. After dissolving the metal nitrates, stoichiometric amount of citric acid is added to the mixture solution to chelate the metal ions. The solution is allowed to evaporate on a hot plate maintaining the solution at temperature $100^{\circ} \mathrm{C}$ to $110^{\circ} \mathrm{C}$. As a result, the concentration of the solution is increased and gel formation is started. A sudden increase in temperature $\left(\mathrm{T}>200^{\circ} \mathrm{C}\right)$ converts the gel into nano-crystalline cobalt ferrite powder. Asprepared powder is calcined $400^{\circ} \mathrm{C}$ for 2 hours in air.

The above prepared samples of pure bismuth ferrite and cobalt ferrite are used to prepare the different multiferroic composites of $(1-\mathrm{x}) \mathrm{BiFeO}_{3}-\mathrm{xCoFe}_{2} \mathrm{O}_{4}$ with $\mathrm{x}=0.0,0.2,0.5,0.8,1.0$. The stoichiometric amounts of the samples are taken and grinded in mortar pestle with water to obtain the homogeneity of the samples. The composites are named as BFO, BFO-CFO1, BFO-CFO2, BFO-CFO3 and CFO respectively for the $\mathrm{x}=0.0,0.2,0.5,0.8,1.0$. The powder is then pressed to form circular pellets by applying pressure. The pellets are sintered at $550^{0} \mathrm{C}$ for 3 hours. The crystal structures of the samples are characterized by X-ray diffractometer (PANalytical X'PERT PRO diffractometer). The surface morphology of the samples is determined by using FEI QUANTA 250 scanning electron microscope (SEM) with energy dispersive X-ray spectroscopy (EDAX). The dielectric properties of the samples are measured by using the Agilent 4284 LCR meter. The room temperature magnetization of the samples is determined as a function of the field using the vibrating sample magnetometer (VSM). The current- voltage (I-V) variation of all the samples is measured at room temperature by using Keithely-2400.

\section{Result and Discussion:- Structural properties:-}

The XRD patterns of the pure bismuth ferrite, cobalt ferrite and their composites are shown in figure 1. The XRD peaks of bismuth ferrite is indexed by ICDD card No. 72-2112 and found to be matched with single phase rhombohedral structure. While for CFO powder, peaks are indexed using the ICDD card No. 22-1086 and is matched with single phase cubic spinel structure. The lattice parameters $a, b$ and $c$ are evaluated by using the Miller indices of the respective planes. Using the Scherrer's formula the crystallite sizes of the samples are determined from the full width half maximum of the dominant peaks (FWHM). The values of the crystallite sizes are reported on the table 1. 


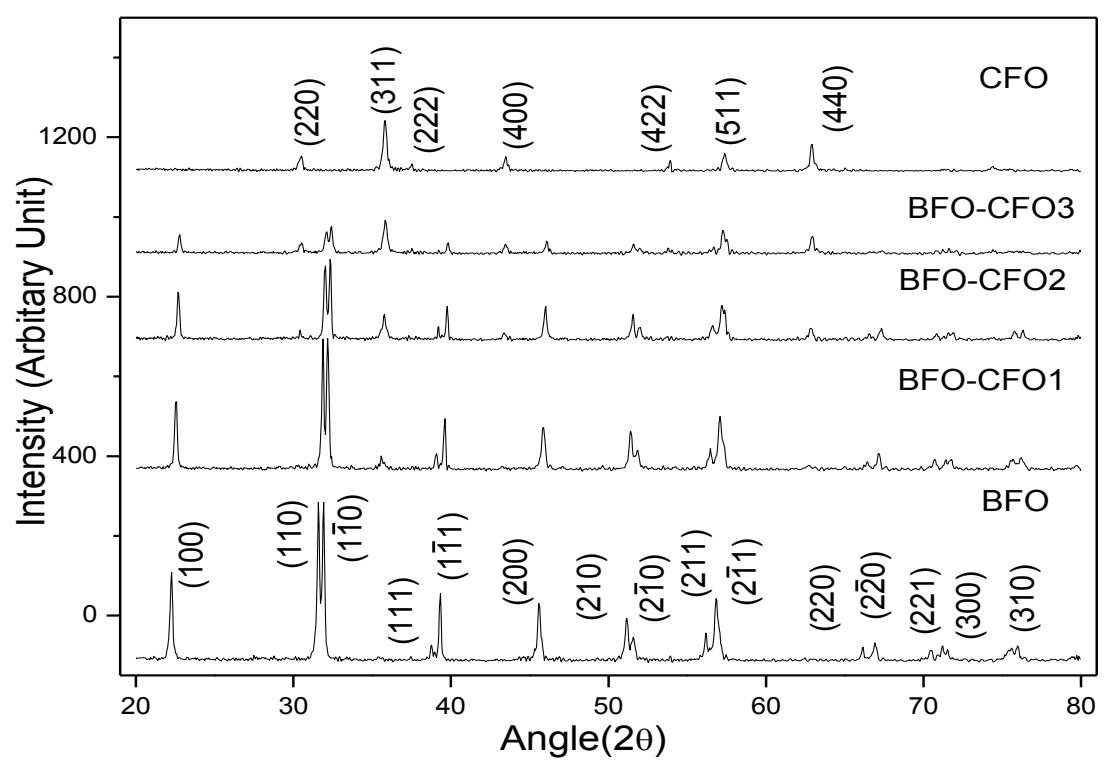

Fig1:- XRD pattern of BFO, CFO and BFO-CFO composites.

In the composite samples, it was found that only the peaks of perovskite BFO and spinel CFO are present in the XRD patterns without any impurities. There is slight change in the peak positions of composites from pure BFO and CFO sample. The XRD peaks of BFO in the composites shifts to the larger $2 \theta$ values with increase in cobalt ferrite. While the XRD peaks of the CFO shifts towards the smaller values with decrease in cobalt ferrite content in the composite samples except the composite BFO-CFO3. This may be related to the distortion of the BFO structure due to the presence of the $\mathrm{CFO}$ in the composites. The composite samples have larger crystallite sizes than that of pure BFO.

\section{Micro structural properties:-}

Fig. 2 shows the SEM images of the bismuth ferrite and cobalt ferrite with their composite samples. Determination of the structure of the sample is very hard from the SEM images. It is observed that there is agglomeration of the particles in the samples. Fig. 3 shows the EDAX of the bismuth ferrite and cobalt ferrite with their composites. EDAX confirms the presences of elements $\mathrm{Bi}, \mathrm{Fe}$, Co and $\mathrm{O}$ expected in the composites with their stoichiometric ratios.
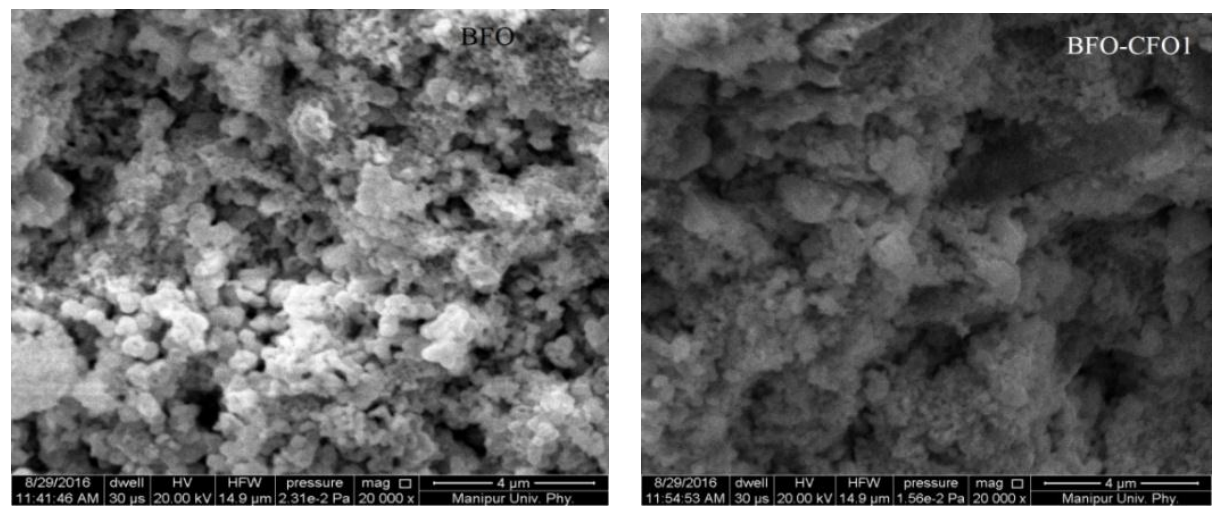

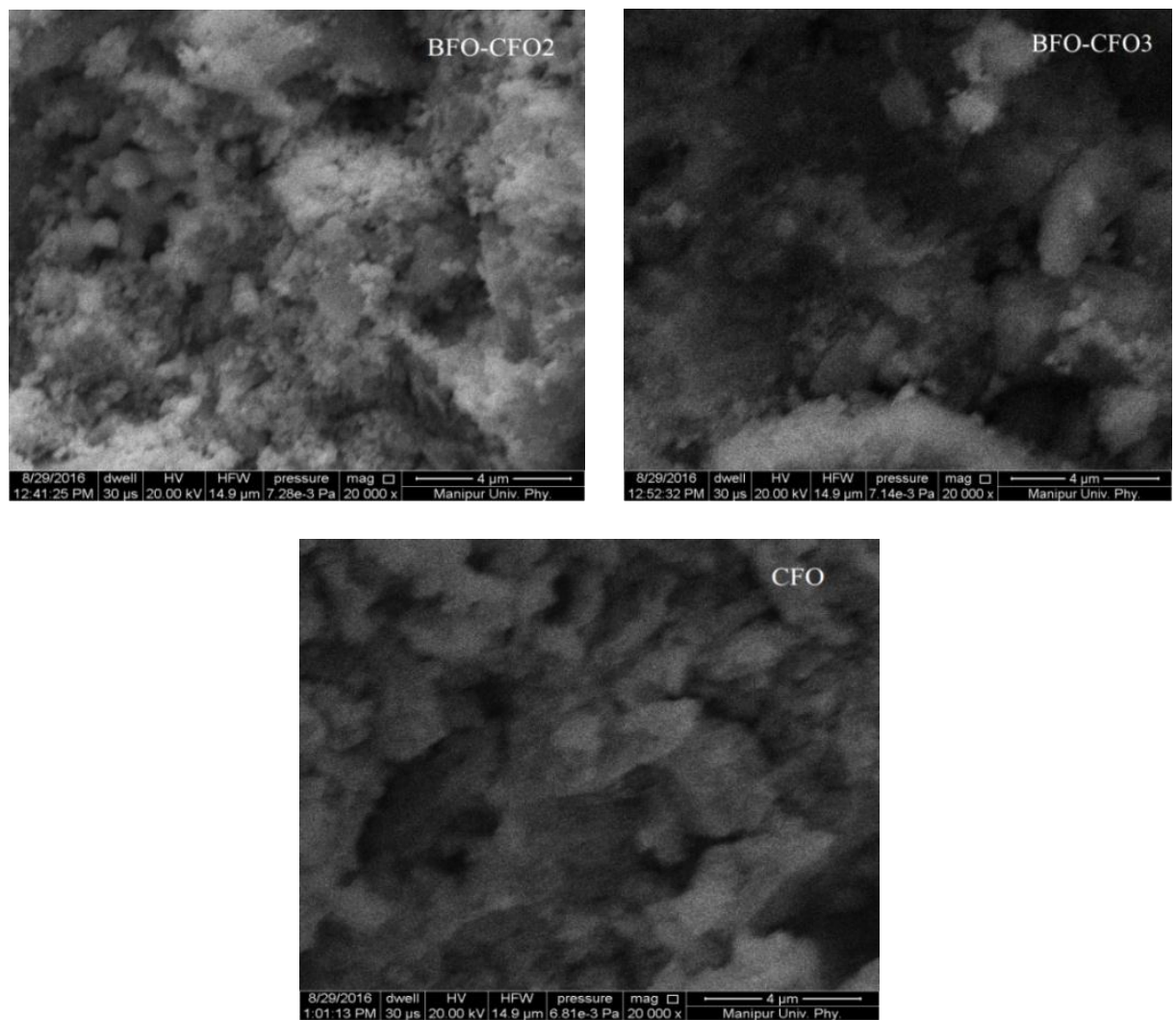

Fig 2:- SEM micrographs of the BFO, CFO and Composites.
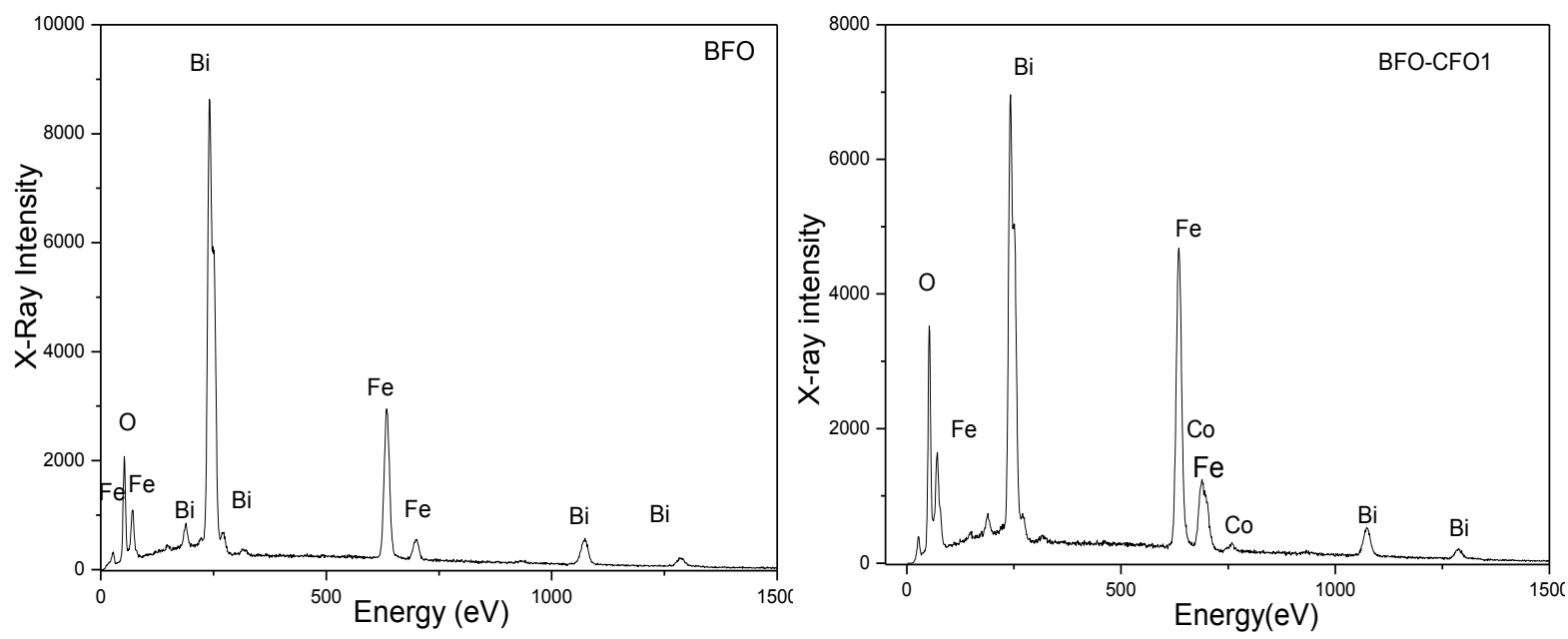


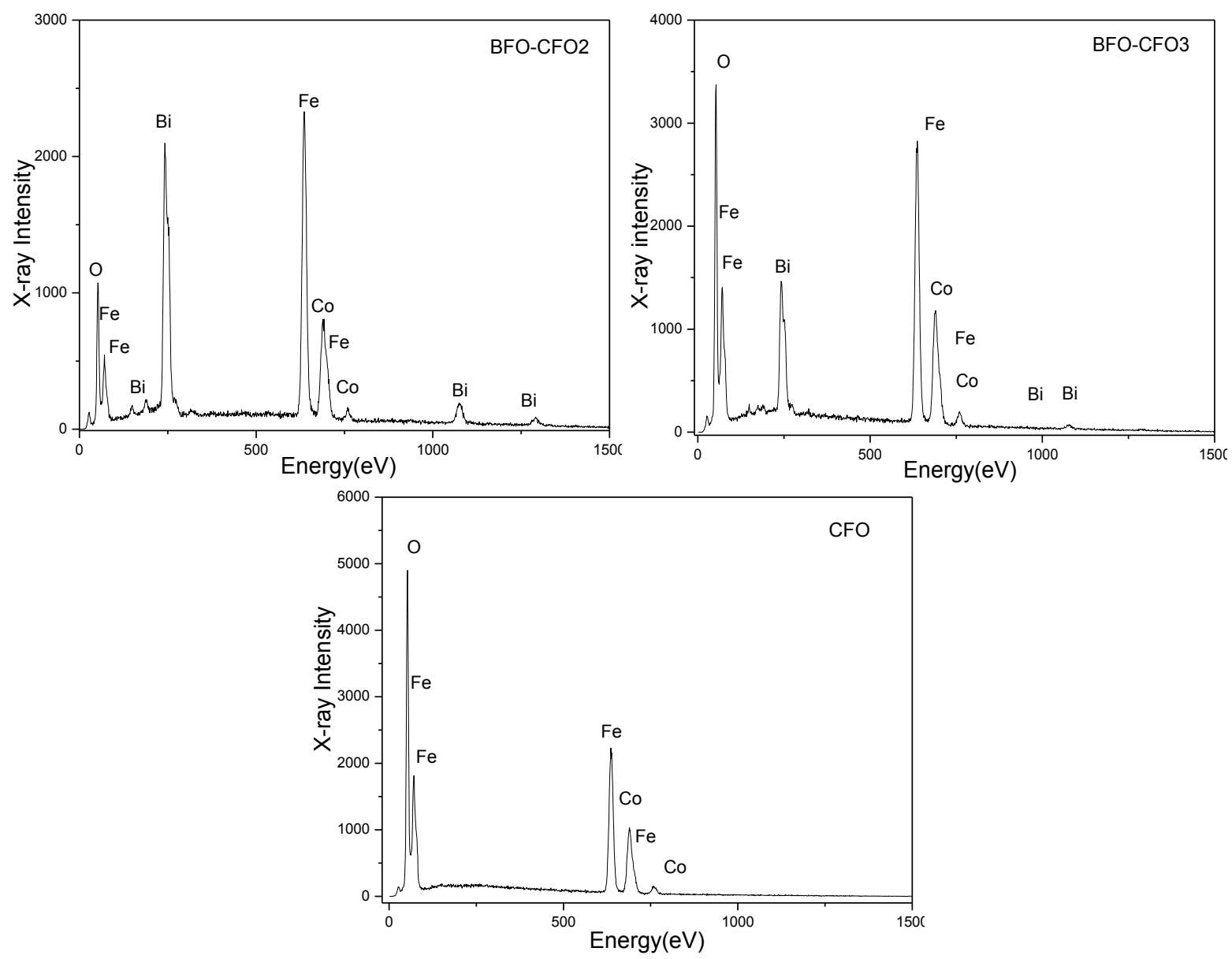

Fig 3:- EDAX image of the BFO, CFO and their composite samples

\section{Dielectric properties:-}

Fig4: shows the variation of dielectric constant $(\varepsilon)$ and dissipation factor $(\tan \delta)$ with frequency $(100 \mathrm{~Hz}$ to $1 \mathrm{MHz})$ at room temperature for $\mathrm{BFO}, \mathrm{CFO}$ and their composites. It is observed that at low frequency all the samples show the frequency dispersion i.e a rapid decrease in the dielectric constant with frequency. It may be attributed to the interfacial polarizations predicted by Maxwell-Wagner model [10-12]. So the decrease in dielectric constant is due to inability of the electron exchanges between the two localized states $\left(\mathrm{Fe}^{+2}\right.$ and $\left.\mathrm{Fe}^{+3}\right)$ to follow the external applied field beyond a certain frequency [13] and non respond of the dipoles due to space charge polarization at higher frequencies. At lower frequencies, the grain boundaries are more effective or contribution from the space charge polarization is high. The space charge polarization is inherently related to non uniform charge accumulation at the grain boundaries due to oxygen vacancy. The dielectric behavior of BFO-CFO composites is found to be higher than the pure BFO at low frequency. The incorporation of cobalt ferrite in bismuth ferrite leads to increase the interfacial area and grain boundary resistance that cause increase in the interfacial polarization. It was also observed that the decrease in the dielectric constant at higher frequency is almost constant because the jumping frequency of the dipoles does not follow the electric field beyond a certain critical frequency. The dielectric constant of BFO decreases slowly with frequency that shows that it is more frequency dependent at higher frequency and has more dielectric constant than the composite samples at higher frequency.

The dissipation factor was found to be decreased sharply at lower frequency and remains almost constant at higher frequency. In general, dissipation factor is due the space charges and interfacial and dipolar polarizations. Dissipation factor was found to be decreased with increase in frequency for all the composites. At low frequency it is due to the accumulation of non-uniform charges at the grain boundary. It may be resistive loss in which the mobile charges consume the energy and relaxation loss in which the relaxation of the dipoles dissipates energy. At lower frequency, high dissipation factor may be attributed to the fact that the hopping frequency of the electrons between the ferrous and ferric ions at the adjacent octahedral sites is same as period of the applied field. But at 
higher frequency, the hoping frequency of the electron exchange between the ferrous and ferric ions doesn't follow the applied field beyond a certain frequency, critical frequency and the dissipation factor has minimum value. The value of dielectric constant and dissipation factor for the samples are presented at table 2.
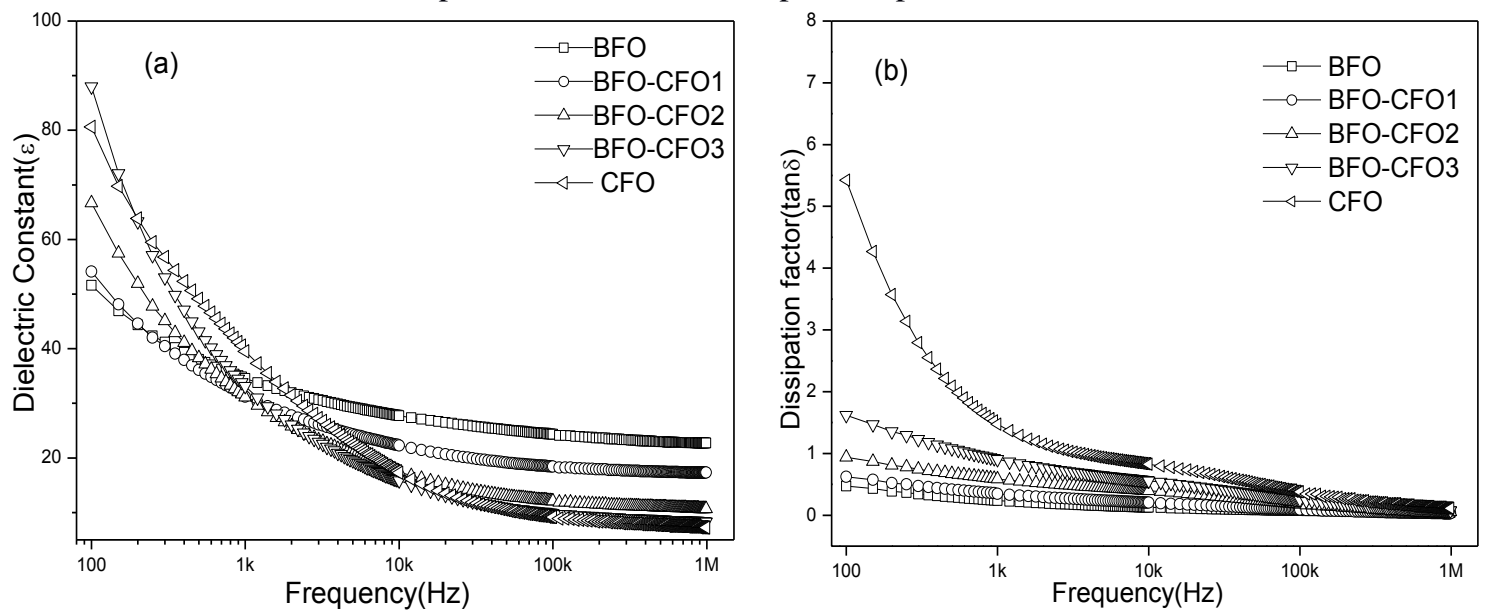

Fig4:- Variation of (a) dielectric constant $(\varepsilon)$ and (b) dissipation factor with frequency at room temperature.
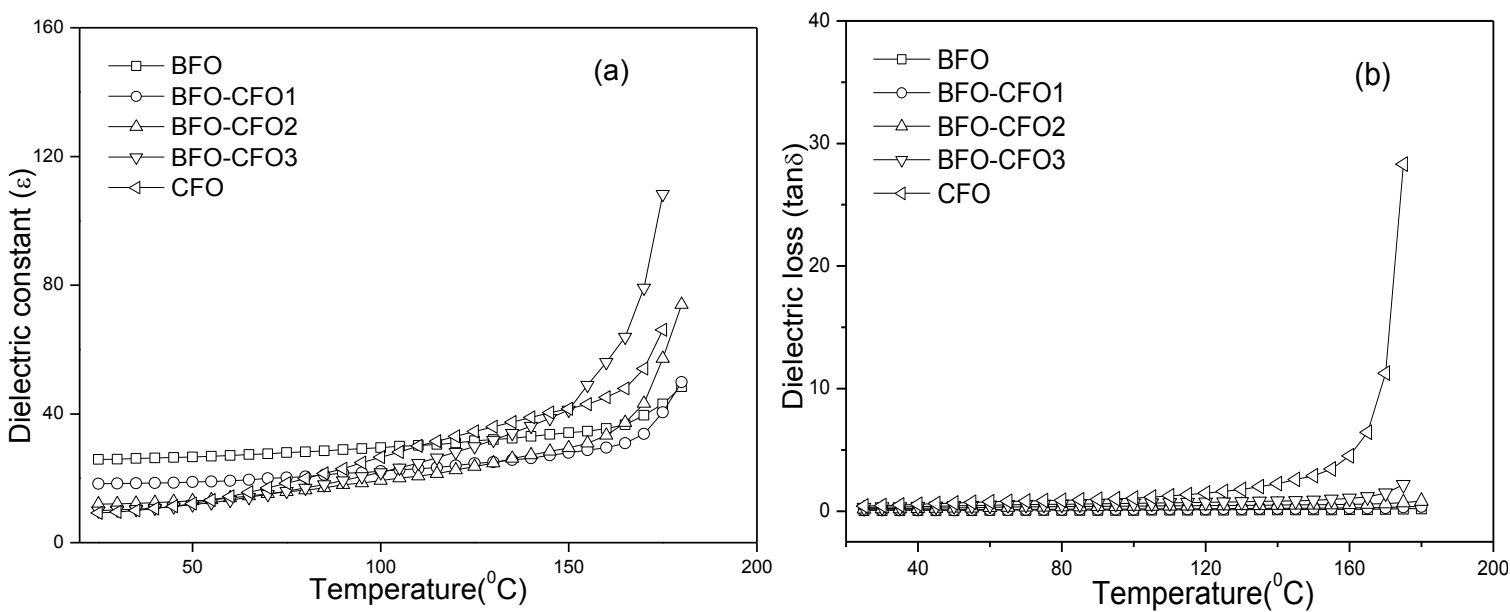

Fig5:- Variation of (a) dielectric constant ( $(\varepsilon)$ and (b) Dissipation factor $(\tan \delta)$ with temperature at $105 \mathrm{KHz}$.

The variation of dielectric constant and dissipation factor with temperature at $105 \mathrm{kHz}$ for BFO, CFO and their composites are shown in figure 5. The dielectric constant increases with increase in temperature for all the composites. The value of dielectric constant still increases but our instrument can measure nearly $200^{\circ} \mathrm{C}$. The ferroelectric phase transition of the pure bismuth ferrite is $\sim 830^{\circ} \mathrm{C}$ while the anti-ferromagnetic to paramagnetic phase transition is $370^{\circ} \mathrm{C}$. Dissipation factor shows an increasing trend with increase in temperature for all the samples. The increase in dissipation factor is attributed due to space charge polarization [14], scattering of thermally activated charge carriers, inherent defects and developed defects in the samples with increase in temperature. This is found that the increasing trend of dissipation factor for cobalt ferrite is maximum compared to the other samples.

\section{I-V Characterization:-}

The current-voltage (I-V) variation of the BFO-CFO composites is shown in the following figures 6. 

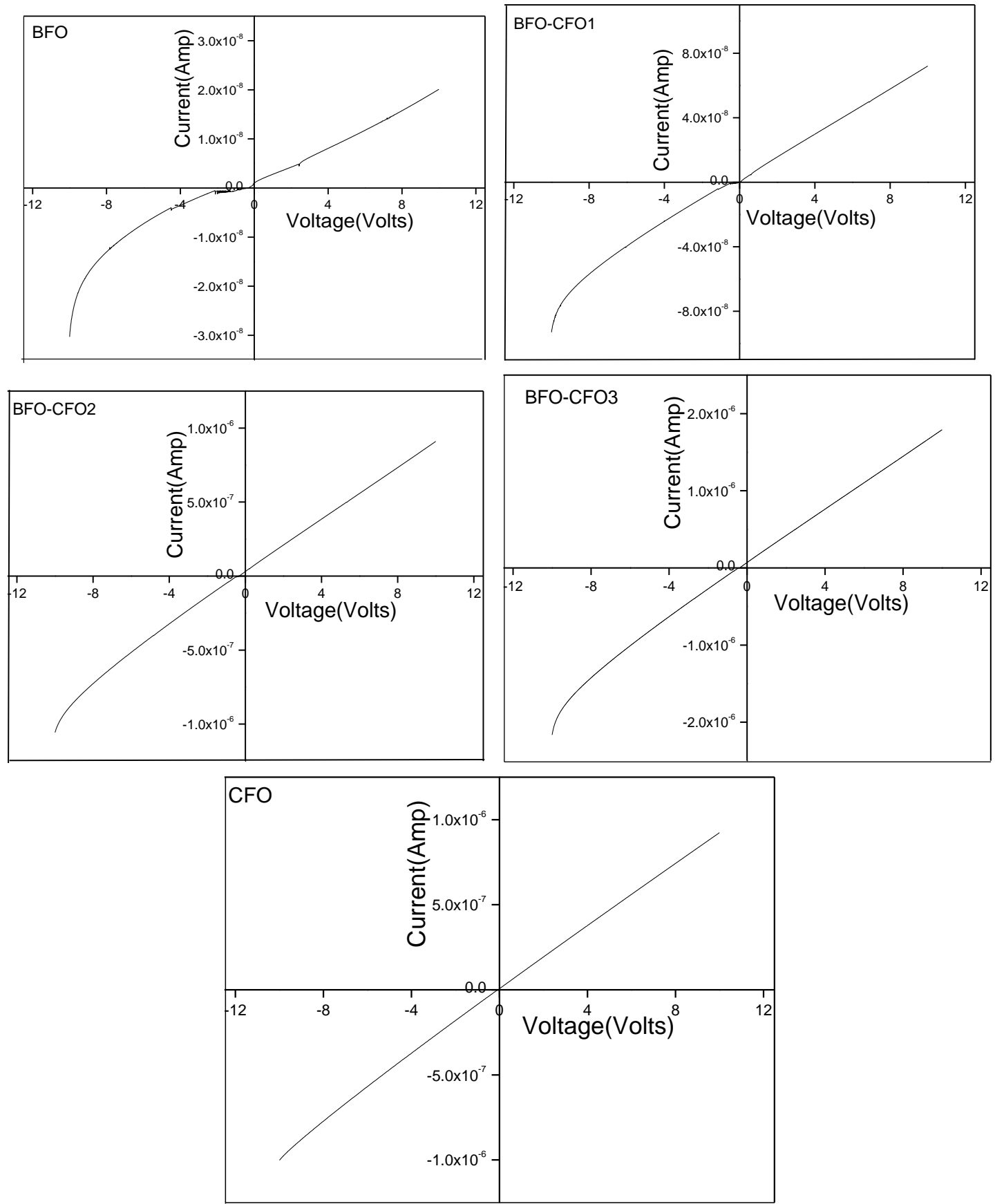

Fig 6:- Characteristic graph of current voltage (I-V) of the different composites of BFO-CFO composites.

The bismuth ferrite sample (BFO) shows slightly the semiconductor behavior as reported in the earlier works in thin films of BFO [15]. When the content of cobalt ferrite (CFO) in the composite samples is increased, ohmic nature of the samples is enhanced as CFO shows the ohmic nature for the range of applied voltage. 


\section{Magnetic properties:-}

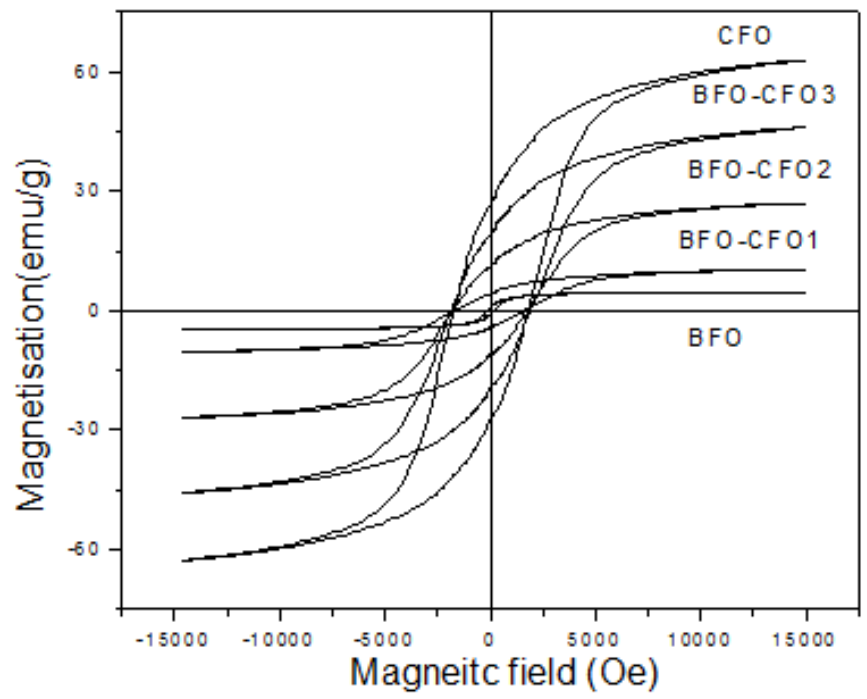

Fig 7:- Magnetic hysteresis loop of BFO, $\mathrm{CFO}$ and their composites at room temperature.

Fig. 7 shows the M-H behavior of the bismuth ferrite, cobalt ferrite and their composites in plane at room temperature. The pure BFO samples show the weak ferromagnetic with coercivity, $\mathrm{H}_{\mathrm{c}}=209.510 \mathrm{O}$ and saturation magnetization, $\mathrm{M}_{\mathrm{s}}=4.72 \mathrm{emu} / \mathrm{g}$. While $\mathrm{CFO}$ shows the strong ferromagnetic properties with $\mathrm{H}_{\mathrm{c}}=1751.8 \mathrm{Oe}$ and $\mathrm{M}_{\mathrm{s}}=62.81 \mathrm{emu} / \mathrm{g}$. The obtained value $\mathrm{M}_{\mathrm{s}}$ of CFO is larger than those reported earlier [16-19].

Table1:- Lattice parameters of BFO-CFO nano-composites.

\begin{tabular}{|c|c|c|c|c|c|}
\hline \multirow{2}{*}{ Sample } & \multicolumn{3}{|c|}{ Lattice parameter } & \multirow{2}{*}{$\begin{array}{c}\text { Crystallite } \\
\text { Size of BFO } \\
(\mathrm{nm})\end{array}$} & $\begin{array}{c}\text { Crystallite } \\
\text { Size of CFO } \\
(\mathrm{nm})\end{array}$ \\
\cline { 2 - 3 } & $\mathrm{CFO}$ & $\mathrm{BFO}$ & $\mathrm{c}(\AA)$ & 86.9 & - \\
\cline { 2 - 4 } & $\mathrm{a}(\AA)$ & $\mathrm{a}(\AA)$ & 5.192 & 153.1 & 34.3 \\
\hline BFO & - & 5.277 & 4.662 & 98.4 & 39.9 \\
\hline BFO-CFO1 & 8.353 & 5.253 & 4.623 & 106.1 & 44.2 \\
\hline BFO-CFO2 & 8.341 & 5.241 & 4.869 & - & 53.2 \\
\hline BFO-CFO3 & 8.338 & 5.159 & - & & \\
\hline CFO & 8.332 & - & &
\end{tabular}

Table2:- Dielectric constant $(\varepsilon)$ and dissipation factor $(\tan \delta)$ of the different composites at room temperature.

\begin{tabular}{|c|c|c|c|c|c|c|}
\hline \multirow{2}{*}{ Sample } & \multicolumn{3}{|c|}{ Dielectric constant $(\varepsilon)$} & \multicolumn{3}{c|}{ Dissipation factor $(\tan \delta)$} \\
\cline { 2 - 7 } & $10 \mathrm{KHz}$ & $100 \mathrm{KHz}$ & $1 \mathrm{MHz}$ & $10 \mathrm{KHz}$ & $100 \mathrm{KHz}$ & $1 \mathrm{MHz}$ \\
\hline BFO & 27 & 24 & 22 & 0.127 & 0.074 & 0.041 \\
\hline BFO-CFO1 & 22 & 18 & 17 & 0.203 & 0.090 & 0.312 \\
\hline BFO-CFO2 & 17 & 12 & 10 & 0.396 & 0.18 & 0.053 \\
\hline BFO-CFO3 & 15 & 9 & 8 & 0.558 & 0.253 & 0.075 \\
\hline CFO & 17 & 9 & 7 & 0.825 & 0.377 & 0.112 \\
\hline
\end{tabular}

Thus the composite samples show the well defined hysteresis loops compared to the pure BFO. The concentration of cobalt ferrite strongly affects the magnetic properties in the composite samples.

Table3:- Magnetic properties of BFO-CFO nano-composites.

\begin{tabular}{|c|c|c|c|c|}
\hline Sample & $\begin{array}{c}\text { Saturation } \\
\text { magnetization } \\
\left(\mathrm{M}_{\mathrm{s}}\right)(\mathrm{emu} / \mathrm{g})\end{array}$ & $\begin{array}{c}\text { Remanence } \\
\text { magnetization } \\
\left(\mathrm{M}_{\mathrm{r}}\right)(\mathrm{emu} / \mathrm{g})\end{array}$ & $\begin{array}{c}\text { Coercivity } \\
\left(\mathrm{H}_{\mathrm{c}}\right)(\mathrm{Oe})\end{array}$ & $\begin{array}{c}\text { Squareness } \\
\left(\mathrm{S}=\mathrm{M}_{\mathrm{r}} / \mathrm{M}_{\mathrm{s}}\right)\end{array}$ \\
\hline BFO & 4.72 & 1.046 & 209 & 0.221 \\
\hline BFO-CFO1 & 10.35 & 4.185 & 1628 & 0.404 \\
\hline BFO-CFO2 & 26.98 & 11.064 & 1772 & 0.410 \\
\hline
\end{tabular}




\begin{tabular}{|c|c|c|c|c|}
\hline BFO-CFO3 & 45.85 & 19.034 & 1866 & 0.415 \\
\hline CFO & 62.807 & 26.805 & 1751 & 0.426 \\
\hline
\end{tabular}

The value of saturation magnetization $\left(M_{s}\right)$, remanence $\left(M_{r}\right)$ and coercivity $\left(H_{c}\right)$ are found to be increased in the composite samples with increasing the cobalt ferrite. The value of the coercivity is found to be maximum for the composite BFO-CFO3 $(\mathrm{x}=0.8)$.

It may be attributed to the magneto-elastic coupling between the anti-ferromagnetic and ferromagnetic phases in the composites. The enhanced magnetization of the composites is attributed due to the magnetic interaction between the compounds and change of the spin orientation of BFO grain at the grain boundary between BFO and CFO. The magnetic property of BFO is strongly affected by addition of CFO and thereby increasing its magnetic properties in the composite samples.

\section{Conclusion:-}

The multiferroic composites of BFO-CFO are synthesized successfully by the sol gel auto-combustion methods. The XRD data confirms the formation of parent compounds. All the composites show the frequency dispersion at low frequency and BFO shows the maximum dielectric constant compared to other composites above $10 \mathrm{KHz}$. The transition temperature of the samples could not be obtained as our instrument measure up to $200^{\circ} \mathrm{C}$. The BFO sample shows minimum ferromagnetism with $\mathrm{H}_{\mathrm{c}}=209.510 \mathrm{e}$ and saturation magnetization, $\mathrm{M}_{\mathrm{s}}=4.72 \mathrm{emu} / \mathrm{g}$ at room temperature. All the samples show the ferromagnetic nature and both saturation and remanence magnetization increase with decrease in BFO in the composites. But there is some variation in coercivity with BFO content and BFO-CFO3 shows the maximum coercivity $\mathrm{H}_{\mathrm{c}}$.

\section{Reference:-}

1. M. Fiebig, Th. Lottermoser, D. Frohlich, A.V. Goltsev, R.V. Pisarev, (2002): Observation of coupled magnetic and electric domains, Nature (London) 419: 818-820.

2. J. Wang, J.B. Neaton, H. Zheng, V. Nagarajan (2003): Epitaxial $\mathrm{BiFeO}_{3}$ Multiferroic Thin Film Heterostructures. Science, 299 (5613): 1719-1722.

3. M. Fiebig, 2005: Revival of the magnetoelectric effect. J. Phys. D, 38: R123-R152.

4. P. Monica, D. Crespo, M. Jose, C.M.S. Preda, 2007:Synthesis and Structural Characterization of Single-Phase $\mathrm{BiFeO}_{3}$ Powders from a Polymeric PrecursorJ. Am. Ceram. Soc.90 (9): 2723-2727.

5. Y.K. Jun, W.T. Moon, C.M. Chang, H.S. Kim, H.S. Ryu, J.W. Kim, K.H. Kim, H.S. Hong 2005:Effects of Nbdoping on electric and magnetic properties in multi-ferroic $\mathrm{BiFeO}_{3}$ ceramics. Soild State Commun.135:133-137.

6. G.L. Yuan, S.W. Or, Y.P. Wang, Z.G. Liu, J.M. Liu 2006: Preparation and multi-properties of insulated singlephase $\mathrm{BiFeO}_{3}$ ceramics. Solid State Commun.138: 76-81.

7. Y.K. Jun, S.H. Hong, (2007): Dielectric and magnetic properties in Co- and Nb-substituted $\mathrm{BiFeO}_{3}$ ceramics. Solid State Commun, 144: 329-333.

8. S.T. Zhang, L.H. Pang, Y. Zhang, M.H. Lu, Y.F. Chen, 2006: Preparation, structures, and multiferroic properties of single phase $\mathrm{Bi}_{1-\mathrm{x}} \mathrm{La}_{\mathrm{x}} \mathrm{FeO}_{3}(\mathrm{x}=0-0.40)(\mathrm{x}=0-0.40)$ ceramics. J. Appl. Phys. 100: 114108.

9. H. Zheng, Q. Zhan, F. Zavaliche, M. Sherburne, F. Straub, M.O. Cruz, L.Q. Cheng, U. Dahmen, R. Ramesh 2006: Controlling Self-Assembled Perovskite-Spinel NanostructuresNano Lett. 6: 1401-1407.

10. C.G. Koops, (1951): On the Dispersion of Resistivity and Dielectric Constant of Some Semiconductors at Audio frequencies. Phys. Rev, 83:121-124.

11. J.C. Maxwell (1933): Electricity and magnetism, Oxford Univ. Press, London.

12. K.W. Wagner, (1993), Ann. Phys. 40: 818.

13. A. R. Shitre, V.B. Kewanee, G.K. Bichile, K. M. Jadhav, (2002): X-ray diffraction and dielectric study of $\mathrm{Co}_{1-\mathrm{x}} \mathrm{Cd}_{\mathrm{x}} \mathrm{Fe}_{2-\mathrm{x}} \mathrm{Cr}_{\mathrm{x}} \mathrm{O}_{4}$ ferrite system. Mater. Lett. 56: 188-193.

14. M.E. Lines, A.M. Glass (1977): Principles and Applications of Ferroelectrics and Related Materials. Oxford University Press, Oxford.

15. Yi-Ting Peng, Shan-Haw Chiou, Ching-Hung Hsiao, Chuenhou (Hao) Ouyang, Chi-Shun Tu (2017): Remarkably enhanced photovoltaic effects and first-principles calculation in neodymium doped $\mathrm{BiFeO}_{3}$. Scientific Reports 7, Article no. 45164

16. RamchandraRao (2011): Magnetic and dielectric properties study of cobalt ferrite nanoparticles synthesized by co-precipitation method. Mater.Res. Soc.Symp.Proc.1368: 40. 
17. H.M. Joshi, Y.P. Lin, Md. Aslam, P.V. Prasad, Elise A. Schultz- Sikma, E. Robert, M. Thomas, V.P. Dravid, (2009): Effects of Shape and Size of Cobalt Ferrite Nanostructures on Their MRI Contrast and Thermal Activation. J. Phys. Chem. C. 113 (41): 17761-17767.

18. Md. G. Naseri, Elias B. Saion, H.A. Ahangar, A.H. Shaari, M. Hashim (2010): Simple synthesis and characterization of cobalt ferrite nanoparticles by a thermal treatment method. J. Nanomater. 2010:1-8.

19. H.B. Sharma, K. Nomita Devi, V. Gupta, J.H. Lee, S. Bobby Singh, (2014): Ac electrical conductivity and magnetic properties of $\mathrm{BiFeO}_{3}-\mathrm{CoFe}_{2} \mathrm{O}_{4}$ nanocomposites. J. Alloy. Compd. 599: 32-39. 